\title{
Specification of functional neurons and glia from human pluripotent stem cells
}

\author{
Yuan Jiang, Mei-Jiang Zhang, Bao-Yang Hu${ }^{\bowtie}$ \\ State Key Laboratory of Reproductive Biology, Key laboratory of Translational Stem Cell Research, Institute of Zoology, Chinese \\ Academy of Sciences, Beijing 100101, China \\ $\triangle$ Correspondence: byhu@ioz.ac.cn \\ Received August 21, 2012 Accepted October 11, 2012
}

\begin{abstract}
Human pluripotent stem cells (PSCs) such as embryonic stem cells (ESCs) and induced pluripotent stem cells (iPSCs) hold great promise in regenerative medicine as they are an important source of functional cells for potential cell replacement. These human PSCs, similar to their counterparts of mouse, have the full potential to give rise to any type of cells in the body. However, for the promise to be fulfilled, it is necessary to convert these PSCs into functional specialized cells. Using the developmental principles of neural lineage specification, human ESCs and iPSCs have been effectively differentiated to regional and functional specific neurons and glia, such as striatal gama-aminobutyric acid (GABA)-ergic neurons, spinal motor neurons and myelin sheath forming oligodendrocytes. The human PSCs, in general differentiate after the similar developmental program as that of the mouse: they use the same set of cell signaling to tune the cell fate and they share a conserved transcriptional program that directs the cell fate transition. However, the human PSCs, unlike their counterparts of mouse, tend to respond divergently to the same set of extracellular signals at certain stages of differentiation, which will be a critical consideration to translate the animal model based studies to clinical application.
\end{abstract}

KEYWORDS pluripotent stem cells, embryonic stem cells, induced pluripotent stem cells, neural stem cell, regenerative medicine, cell transplantation

\section{INTRODUCTION}

The possibility of generating abundant differentiated cells from human stem cells for cell replacement therapies provides a plausible avenue to treat such diseases as degenerative diseases and tissue injury. To replace the degenerated tissues or damaged organs with exogenous cells for functional recovery, a wealth of appropriate type of cells are necessary for transplantation. Neural stem cells that are isolated from adult donors or from fetal brain tissue have been considered a reasonable source of cells for this purpose; however, adult neural stem cells are of very limited quantity and are far from adequate for practical transplantation. Fetal neural stem cells neither are ideal because of the ethical concerns of destroying fetus. In addition, although both adult and fetal neural stem cells in theory are able to be amplified using mitogens such as FGF2 or EGF, these neural stem cells always undergo undesired differentiation and tend to lose their potential to generate the appropriate type of cells for cell replacement therapy (Wright et al., 2006). Functional neurons (Vierbuchen et al., 2010; Ambasudhan et al., 2011; Marro et al., 2011; Pang et al., 2011; Qiang et al., 2011; Yoo et al., 2011), and lately subtype-specific neurons such as dopaminergic neurons (Caiazzo et al., 2011; Pfisterer et al., 2011) and motor neurons (Son et al., 2011) have been converted directly from other type of somatic cells of mouse and human by introducing pro-neuronal transcription factors or micro-RNA. The neurons generated through these procedures were called induced neurons (iNs) and the process was termed transdifferentiation. Transdifferentiation from other type of somatic cells into functional neurons has allowed the generation of mature neurons in a relatively shorter period, which seems to be an ideal source of cells for transplantation, nevertheless, the efficiency of transdifferentiation is low, and the iNs are not expandable for large quantity. Alternative procedures that convert other type of somatic cells into expandable neural stem cells are also under extensive exploration (Kim et al., 2011; Han et al., 2012; Lujan et 
al., 2012; Ring et al., 2012; Sheng et al., 2012; Thier et al., 2012). In contrast to the iNs, the induced neural stem cells (iNSCs) are capable to proliferate, thus allow yield of larger quantity of cells through selectively amplification of the induced neural stem cells. In this regard, they may seem superior to iNs; yet, there are still obstacles ahead for them to be a rational source of cells for transplantation. On top of the task list is to develop genomic non-integration protocols for neural stem cell induction. So far, the current protocols of neural stem cells induction are immature; moreover, specificity of the induced neural stem cells remains to be improved.

Human pluripotent stem cells (PSCs), including embryonic stem cells (ESCs) that are derived from inner cell mass, and induced pluripotent cells (iPSCs) that were reprogrammed from somatic cells by a set of pluripotent factors, in theory are able to generate any type of cells of the body while retaining the ability of self-renewal (Thomson et al., 1998; Takahashi et al., 2007; Yu et al., 2007). Of these, hESCs have been prevalently studied over the last two decades and the findings founded a platform for the derivation of human iPSCs. In spite of the ethical concerns of hESCs and the current sub-optimized reprogramming methods of iPSCs, these categories of cells are likely more appropriate for industrial production and standardization, thus represent an important source of cells that hold great promise in regenerative medicine. Human iPSCs, in addition, allow for personalized cell therapy through correction of disease gene prior to or following reprogramming patients' cells (Dimos et al., 2008; Ebert et al., 2009; Lee et al., 2009). In any case, a key step toward using these cells for cell replacement therapy is to convert these pluripotent stem cells into functionally specialized cells, such as neurons and glia of the nervous system. In this review, we will overview the current conceptual updates of the pluripotency and human PSCs, revisit the principles that were adopted to device the neural differentiation protocols, summarize the procedures that were employed for differentiation of the typical types of neuronal and glial cells of the central nervous system, paying particularly attention to the cells derived from the ventral neural tube, and highlight the significant differences of neural differentiations between human and mouse ESC.

\section{REVISITING THE PLURIPOTENCY OF HESCS}

Our knowledge of stem cells and pluripotency mostly come from studies on the mouse system. Studies on mouse PSCs have revealed the basic machinery that regulates the pluripotency, self-renewal and differentiation. The identification of a conserved pluripotency circuitry that orchestrated by the core pluripotent factor Oct4 with Sox2 and Nanog has invaluable significance in understanding the fundamental aspects of human PSCs. However, fundamental differences exist between these two types of PSCs. Although pluripotent factors such as Oct4, Sox2 and Nanog are conserved in both human and mouse PSCs, the downstream cascade and the fine-tuning machineries may vary. Most obviously, they need different culture conditions and exhibit significant difference in colony morphology, growth rate, surface markers, and differentiation potential. Their differences were further demonstrated by the global molecular signatures (Sato et al., 2003; Rao, 2004) and the signaling pathways (Okita and Yamanaka, 2006) that regulating self-renewal and differentiation. Whether the dissimilarity between these two type of ESCs is because of the intrinsic difference between species or simply due to an unmatchable developmental stages of these two types of PSCs (Rossant, 2008) have become a critical question of human stem cell biology. From the postimplantation epiblast of mouse, another type of pluripotent stem cells, EpiSCs were derived. These mouse EpiSCs exhibit substantially similarity to hESCs in various aspects such as culture condition, molecular signature, transcriptional networks, and epigenetic status (Brons et al., 2007; Tesar et al., 2007). These new findings to some extent may indicate that the difference between mouse and human ESCs might be attributed to the distinct developmental stages these two types of PSCs each represent, and the hESCs are in fact a human equivalence of moue EpiSC. However, the portion that the specie-specific difference contributed has not been completely excluded.

Although hESC lines from different sources seem similarly under an undifferentiated state, they vary considerably upon differentiation. Some hESC lines have a propensity to differentiate into certain lineages or cell types: HUES 8 favors pancreatic fate while HUES 3 prefers to differentiate into cardiomyocytes (Osafune et al., 2008). Propensity also exists when subtype of cells are differentiated from a specific lineage. For instance, HSF1 primarily form forebrain neurons whereas HSF6 predominantly produce hindbrain, cervical and thoracic neurons (Wu et al., 2007). The bias of neural differentiation seems getting much more significant in hiPSCs, regardless of how the hiPSCs was derived (Hu et al., 2010). The variable potency of different lines of PSCs may be a result of the native heterogeneity of the starting cells that were chosen for expansion, which calls for identification of novel marks that could characterize those cells with real pluripotency.

\section{DEVELOPMENTAL PRINCIPLES OF THE NEURAL SPECIFICATION AT THE VENTRAL NEURAL TUBE}

During early development, neural differentiation starts when neural ectoderm, a portion of the ectoderm is differentiated from the surrounding parts. The earliest neural stem cells capable of generating all types of neurons and glia come from the neural plate, a disk-like region in the middle part of ectoderm. The neural plate, with the lateral parts folding outwards and merging together along the midline, forms a tube-like structure named neural tube. The neural stem cells in the neural tube, in response to gradients of morphogens, such as 
retinoid acid (RA) and Sonic Hedgehog (SHH) differentiate and acquire their precise positional identity (anterior-posterior and dorsal-ventral). Within the developing brain, a gradually decreased concentration of $\mathrm{SHH}$ patterns the ventral part of the brain into the medial ganglionic eminence (MGE) at ventral, and the lateral ganglionic eminence (LGE) at dorsal (Wichterle et al., 2001); whereas in the ventral spinal cord, a gradient of $\mathrm{SHH}$ defines five exclusive domains that express distinct transcription factors such as Nkx2.2, Nkx6.1, Olig2, Irx3, and Pax6. Right next to the most ventral domain, cells expressing Olig2 form a small region named $\mathrm{pMN}$ domain. Cells in the pMN domain adopt diverse fate in a temporarily restricted manner, with motor neurons differentiated first and oligodendrocytes thereafter (Fancy et al., 2011). As hESCs represent a universal population of cells in the inner cell mass, a similar patterning principles ought to work in the hESC derivatives and guide their neural specification.

\section{NEURAL DIFFERENTIATION OF HESCS RECAPITULATES THE EARLY DEVELOPMENT OF NEURAL TUBE}

The human pluripotent stem cells such as hESCs, although cultured in vitro for multiple passages, sustain the same potential as those in the inner cell mass and adopt a similar program upon differentiating into the neural lineage. To different hESCs in vitro, a chemically defined culture system was developed after the knowledge of developmental biology, in which the human PSCs are isolated from feeder cells to form cell aggregates in suspension. These cell aggregates form spheres in the following days and start their differentiation program upon withdrawal of mitogens. Such human PSCs grown in suspension prefer a fate of neuroepithelia that express anterior marker Pax6 at day 7 of differentiation, unless they are forced patterned by additional morphogens for alternative fate. These earliest primitive cells, if attached on a culture surface for another week, will form typical rosettes, settes, and the cells within the rosettes express additional neural markers such as Sox1 (Zhang et al., 2001; Pankratz et al., 2007) (Fig. 1). Activating FGF signaling, and/or inhibiting SMAD pathway, significantly improves the neural differentiation (Chambers et al., 2009; LaVaute et al., 2009). The PAX6-expressing primitive neural epithelial cells are ready to response to morphogens, especially to the RA signaling for caudalization. However, the period that is permissive for caudalization last only for a few days. When the cells convert to definitive neural epithelial cells by day 15 of differentiation, they become completely irresponsible to RA. Thus, in order to differentiate spinal cells from human PSCs, RA is usually added to the primitive neural epithelial cells of day 10 prior to administration of other morphogens. The sequential expression of these neural markers perfectly matches the programmed appearance of the primitive and definitive neural epithelium within the neural tube, and the neural differentiation of hESCs recapitulates the early development of neural tube. Alternatively, hESCs can be differentiated in a feeder free system under adherent culture conditions, in which the hESC colonies were treated with Noggin and SB431542, two inhibitors of SMAD signaling (Chambers et al., 2009). This protocol was able to convert effectively over $80 \%$ of hESCs into PAX6 + neural cells within a week. Neural differentiation seems accelerated with this protocol; yet, the amount of the generated neural cells will critically be contingent upon the initial quantity of hESCs used for differentiation, as the neural cells quickly undergo postmitotic upon differentiation. In addition, fine tuning of subtype specification becomes more difficult because of the vague demarcation between stages.

\section{DIFFERENTIATION OF THE LGE LIKE CELLS AND THE STRIATAL GABAERGIC NEURONS}

By default, human ESCs adopt a rostral and dorsal brain fate unless signaling such as RA or SHH is activated in the early

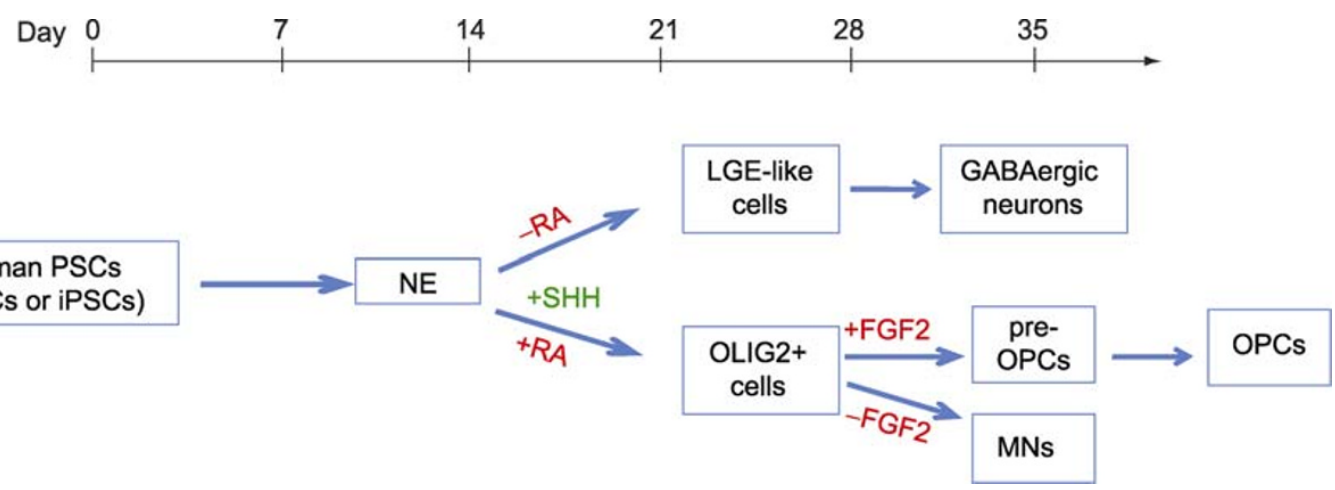

Figure 1. Specification of neurons and glia from human PSCs. The hPSCs are converted into neuroepithelia within 2 weeks after the initiation of differentiation. In the presence of $\mathrm{SHH}$, the NE is then treated with RA for OLIG2+ spinal progenitors or without RA for LGE-like cell specification. By the end of the 5th week, the LGE-like cells are differentiated into GABAergic neurons and the OLIG2+ cells are converted into MNs upon SHH removal. In the presence of FGF2 for a week, the spinal OLIG2+ cells become pre-OPCs that express both OLIG2 and NKX2.2 at the 5th week. Upon removal of FGF2, the pre-OPCs differentiate into OPCs eight more weeks later. 
neuroepithelia. In the presence of $200 \mathrm{ng} / \mathrm{mL}$ of $\mathrm{SHH}$ for a week, the neuroepithelial cells become expressing Gsx2 and modest Pax6, resembling the phenotypes of LGE cells in the brain. After SHH removal, these LGE-like progenitors further differentiate into medium size GABAergic neurons that express other specific markers such as GABA, glutamic acid decarboxylase (GAD) 65/67, and DARPP32, in addition to the striatal markers Meis2 and Ctip2 (Figs. 1 and 2C). After 5 weeks of differentiation, this procedure typically generates as high as $87 \%$ of DARPP32-expressing GABAergic neurons (Ma et al., 2012). These human PSC derived medium spiny GABAergic neurons, when transplanted into the mouse striatum in which the GABAergic neurons were destroyed, were able to reconstitute the GABAergic circuits and correct the locomotive deficits (Fig. 2F). Importantly, this same task of structural restoration and functional recovery was not accomplished by the ventral spinal neurons that are derived from the same line of PSCs (Fig. 2F), indicating that the specificity of a given type of neurons plays an important role for appropriate functional reparation.

\section{TWIST BETWEEN SPINAL MOTOR NEURON AND OLIGODENDROCYTES}

The human PSC derived primitive neural epithelial cells are responsive to $\mathrm{RA}$ and adopt spinal cell fate in the presence of low dosage of RA. Next, in order to differentiate the ventral spinal cells, specifically motor neurons (MN) (Li et al., 2005; $\mathrm{Hu}$ and Zhang, 2009) and oligodendrocytes (OL) (Hu et al., 2009a), the early neuroepithelia were treated with $0.1 \mu \mathrm{mol} / \mathrm{L}$ of RA during day 10-17 of differentiation. This will have these naïve neural stem cells adopt spinal cell fate and subsequently differentiate into more specific subtypes of neurons or glia. During the third week, $100-200 \mathrm{ng} / \mathrm{mL}$ of $\mathrm{SHH}$, or its agonist purmorphamine at $1 \mu \mathrm{M}$ was administrated to further restrict these cells to ventral spinal cells that express OLIG2. These treatments resulted in over $60 \%$ of Olig2-expressing progenitors by the end of the 4th week and up to $50 \%$ of Mnx1 (also known as HB9)-expressing motor neurons another week after (Figs. 1 and 2A). These human PSC-derived MNs, with additional trophic factors such as GDNF, IGF
A

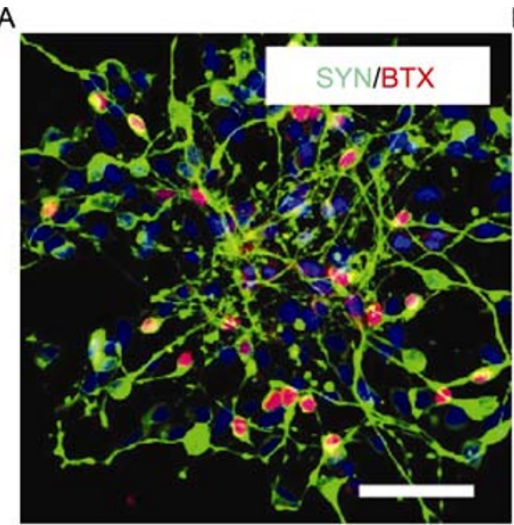

D



B
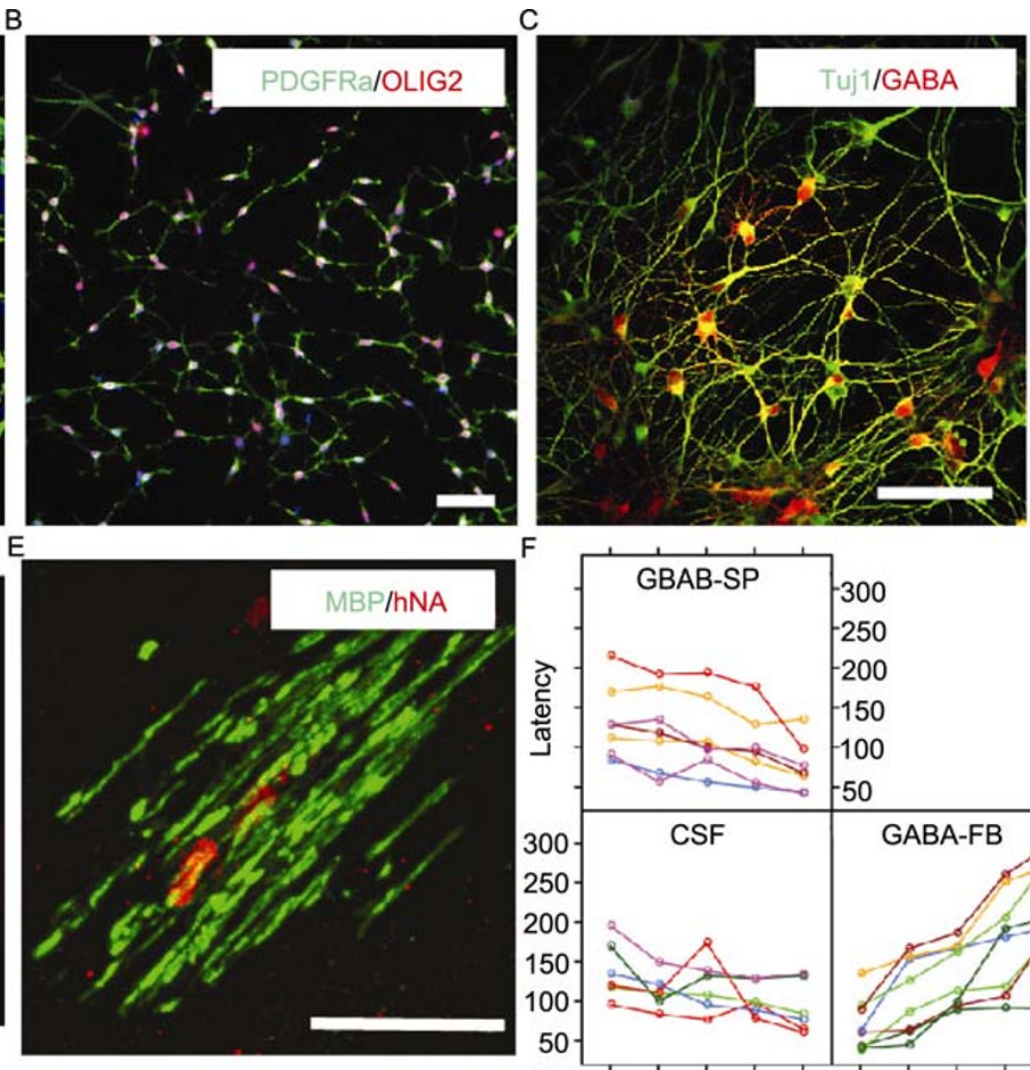

Figure 2. Neurons and glia differentiated from hESCs. (A-C) Motor neurons, oligodendrocytes and GABAergic neurons derived from hPSCs. (D-F) Functional properties of the human PSC-derived neurons and glia. (D) BTX labeling showing motor neurons promote aggregation of acetylcholine receptors on myotubes. (E) Graft OPCs form myelin sheath in shiverer mice. (F) Rota-rod tests showing increased latency in animals that received forebrain GABAergic neuron (GABA-FB) but not ventral spinal neuron (GABA-SP) transplantation. Scale bar $=50 \mu \mathrm{m}$. 
and BDGF added, gradually become mature, evidenced by their ChAT expression and electrical activity. In order to prove the function ability of these hPSC-derived MNs, they were co-cultured with myoblasts in a petri-dish to mimic a scenario of nerve-muscular junction formation. A week later, the hPSC-derived MNs are able to prompt the clustering of acetylcholine receptors on myotubes, indicating the formation of nerve-muscular junction. Aggregated acetylcholine receptors are able to be labeled with fluoresce conjugated bungarotoxin (BTX) (Fig. 2D).

During development, Olig2+ cells in the pMN domain also give rise to oligodendrocytes. In order to produce myelin sheath forming oligodendroglial precursor cells (OPCs) from human PSCs, the human PSC derived Olig2- expressing ventral spinal progenitors were briefly treated with $10 \mathrm{ng} / \mathrm{mL}$ of FGF2 from day 23 for a week. FGF2 almost completely prevents the Olig2-expressing cells from differentiating into MNs, and increases a population of cells co-expressing Olig2 and Nkx2.2, termed pre-OPCs. By the fifth week of differentiation, over $80 \%$ of pre-OPCs could be obtained from a typical differentiation setup. However, these pre-OPCs do not become bipolar Sox10/PDGFR-co-expressing OPCs until 2 months later (Figs. 1 and 2B). During the 2-month differentiation of OPCs from pre-OPCs, continued $\mathrm{SHH}$ signaling activation and sustained Olig2 expression is required. FGF2, which was used for enriching the Olig2-expressing cells and promoting the generation of pre-OPCs, inhibits the further differentiation of OPCs, at least partly through antagonizing $\mathrm{SHH}$ signaling. To verify the functionality of these human PSC derived OPCs, a line of mouse named shiverer was used as a model of hypomyelination. Since MBP is mutated in these mice, MBP is not expressed within their brain and there is no compacted myelin sheath surrounding the nerve fibers. The hPSC-derived OPCs, upon transplantation into the brains of shiverer mice, are able to differentiate into mature oligodendrocytes that can re-myelinate the hypo-myelinated nerve fibers, indicating these in vitro-produced cells have gained the authentic function of oligodendrocytes (Hu et al., 2009a, 2009b) (Fig. 2E).

\section{DIFFERENTIATION OF REGIONAL SPECIFIC ASTROCYTES}

Astrocytes represent another type of glia that are essential for normal development and proper functions of the nervous system. Their malfunction contributes to a number of diseased conditions such as Amyotrophic lateral sclerosis (ALS) (Di Giorgio et al., 2008; Marchetto et al., 2008). Functional astrocytes can be differentiated from human PSCs, also based on the developmental principles of the nervous system, but over a much longer period of nurturing. Consistent with normal development of human, during which astrocytes are differentiated following the appearance of neurons (Wilkinson et al., 1990; Pal et al., 1999), astroglial progenitors or imma- ture astrocytes that express NFIA-S100 $\beta$ can be coaxed from hESCs in between 4 and 8 weeks of differentiation. After another 4-8 weeks of differentiation, these cells express additional markers of the astroglia lineage, such as CD44-GFAP, and at day 180, almost all the hESC derived astrocytes expressed NFIA (Krencik et al., 2011).

Similar to neurons, astrocytes in the nervous system bear unique regional identity and distinctive functions. Using a same strategy as that for neuronal differentiation, astrocytes that have specific regional identity can be differentiated from hESCs. A ten-day treatment of $0.5 \mu \mathrm{mol} / \mathrm{L}$ of RA or $50 \mathrm{ng} / \mathrm{mL}$ of fibroblast growth factor 8 (FGF8) is able to convert the $\mathrm{hESC}$ derived primitive neuroepithelial cells into spinal or mid-brain astrocytes, respectively. SHH signaling, in addition is implicated as a switch for a dorsal or ventral fate of the differentiated astrocytes. These hESC derived astroglial cells, when co-cultured with neurons, exhibited significant morphological alterations and a remarkable decrease of transient outward current, indicating that these astroglia get mature in vitro. Upon transplantation into the mouse brain, these cells were able to incorporate into the host brain and sustained their original regional identity that was patterned in vitro (Krencik et al., 2011).

\section{DISTINCTIVE NEURAL DIFFERENTIATION OF HUMAN PSCS}

Conservation between the species is the primary driving force to utilize animal models studying human biology. As mentioned above, studies on multiple models vary from fly and worms to rodents have enabled the identification of the core circuitry of pluripotency with Oct4 as the central player. This further facilitates the isolation, verification and in vitro culture of mESCs, and later hESCs. However, it is nearly two decades after the isolation of mESCs that the hESC line was first established in 1998. One reason of this delay is the huge difference between mouse and human in response to certain extracellular signals. BMP signaling, which maintains the pluripotency of mESCs, promote the hESC to differentiate, preferably into trophblast (Xu et al., 2002). In contrast, the FGF2, which is routinely used in hESC culture, initiate the differentiation of mESCs (Lanner and Rossant, 2010). The similar scenario seems exist during the neural differentiation from ESCs as well. For instance, transcription factor Pax6, as a determinant of neuroectoderm in humans, is necessary and sufficient for primitive neuroepithelia specification from hESCs, but not from mouse ESCs (Zhang et al., 2010). This may be one of the reasons why human PSC-derived neural progenitors preferentially adopt the cerebral cortical fate. The early expression of PAX6 in neuroectoderm may allow the cells to proliferate comprehensively so as to produce abundant of neurons that constitute the evolutionary advanced human brain. Dissimilarity also exists during the transition from pre-OPCs into OPCs. When differentiating mESCs into 
OPCs, FGF2 is able to convert the Olig2-expressing cells into OPCs efficiently (Du et al., 2006). For differentiation of human oligodendrocytes, the presence of FGF2 in cultures promote the generation of pre-OPCs from Olig2-expressing cells, however, these pre-OPCs will not convert into OPCs if FGF2 is presented in the culture (Hu et al., 2009a). The difference seems not simply a result of stretched timing of human OPC differentiation, but reflects the intrinsic features that humans differentiate themselves from mice. Thus, one important issue of human stem cell research is to identify the distinctiveness of human cells, including the stretched timing of differentiation, the divergent response to the same extracellular signaling at certain stage of neural differentiation, and sometimes a combination of both. Given the long course of differentiation and the yet to be identified stages that human cells may response divergently to certain cell signals, to develop, or optimize the protocols for neural subtypes specification from human PSCs is never an easy task. The divergence in neural differentiation is also an important issue when considering the translation of animal studies into clinical application.

\section{FUTURE PERSPECTIVE OF NEURAL DIFFERENTIATION AND THE RELATED TECHNOLOGIES}

Based on the principles of developmental biology, a set of neurons and glia that bear the authentic features of their counterparts in vivo has been successfully differentiated from human PSCs. These neurons and glia were proved to be functional in vitro and were able to correct the functional deficits when transplanted into the animal models. The reliable way to produce functional cells from hPSCs is instrumental to translate stem cell research into regenerative medicine. Nevertheless, there are still a lot of issues remaining to be solved before this translation is to be realized. For instance, the proportion of desired types of cells is not high enough for effective therapy; the graft may be immuno-rejected by the host because of the nature of allograft of different individuals; the diseased microenvironment of the recipient may affect the survival and functional integration of the graft cells into the host. These issues will be the hot topics in the field of regenerative medicine and will be extensively studied in the next few years. As a result of the perfections of human PSC neural differentiation, technologies of reprograming and transdifferentiation may also get optimized. With the procedures further refined for scalable production of clinical approved neurons and glia, and concurrent resolution of other issues that hinder the clinical application of hPSC derivatives, curing neurological diseases such as Huntington Diseases and spinal cord injury may be within reach.

\section{ACKNOWLEDGEMENTS}

This work was supported by grants from the Ministry of Science and
Technology of China (No. 2012CB966300), the National Natural Science Foundation of China (Grant No. 31171430) and the "Strategic Priority Research Program" of the Chinese Academy of Sciences (No. XDA01040109).

\section{REFERENCES}

Ambasudhan, R., Talantova, M., Coleman, R., Yuan, X., Zhu, S., Lipton, S.A., and Ding, S. (2011). Direct reprogramming of adult human fibroblasts to functional neurons under defined conditions. Cell Stem Cell 9, 113-118.

Brons, I.G., Smithers, L.E., Trotter, M.W., Rugg-Gunn, P., Sun, B., Chuva de Sousa Lopes, S.M., Howlett, S.K., Clarkson, A., Ahrlund-Richter, L., Pedersen, R.A., et al. (2007). Derivation of pluripotent epiblast stem cells from mammalian embryos. Nature 448, 191-195.

Caiazzo, M., Dell'Anno, M.T., Dvoretskova, E., Lazarevic, D., Taverna, S., Leo, D., Sotnikova, T.D., Menegon, A., Roncaglia, P., Colciago, G., et al. (2011). Direct generation of functional dopaminergic neurons from mouse and human fibroblasts. Nature 476, 224-227.

Chambers, S.M., Fasano, C.A., Papapetrou, E.P., Tomishima, M., Sadelain, M., and Studer, L. (2009). Highly efficient neural conversion of human ES and iPS cells by dual inhibition of SMAD signaling. Nat Biotechnol 27, 275-280.

Di Giorgio, F.P., Boulting, G.L., Bobrowicz, S., and Eggan, K.C. (2008). Human embryonic stem cell-derived motor neurons are sensitive to the toxic effect of glial cells carrying an ALS-causing mutation. Cell Stem Cell 3, 637-648.

Dimos, J.T., Rodolfa, K.T., Niakan, K.K., Weisenthal, L.M., Mitsumoto, H., Chung, W., Croft, G.F., Saphier, G., Leibel, R., Goland, R., et al. (2008). Induced pluripotent stem cells generated from patients with ALS can be differentiated into motor neurons. Science 321 , $1218-1221$.

Du, Z.W., Li, X.J., Nguyen, G.D., and Zhang, S.C. (2006). Induced expression of Olig2 is sufficient for oligodendrocyte specification but not for motoneuron specification and astrocyte repression. Mol Cell Neurosci 33, 371-380.

Ebert, A.D., Yu, J., Rose, F.F., Jr., Mattis, V.B., Lorson, C.L., Thomson, J.A., and Svendsen, C.N. (2009). Induced pluripotent stem cells from a spinal muscular atrophy patient. Nature 457, 277-280.

Fancy, S.P., Chan, J.R., Baranzini, S.E., Franklin, R.J., and Rowitch, D.H. (2011). Myelin regeneration: a recapitulation of development? Annu Rev Neurosci 34, 21-43.

Han, D.W., Tapia, N., Hermann, A., Hemmer, K., Hoing, S., Arauzo-Bravo, M.J., Zaehres, H., Wu, G., Frank, S., Moritz, S., et al. (2012). Direct reprogramming of fibroblasts into neural stem cells by defined factors. Cell Stem Cell 10, 465-472.

Hu, B.Y., Du, Z.W., Li, X.J., Ayala, M., and Zhang, S.C. (2009a). Human oligodendrocytes from embryonic stem cells: conserved $\mathrm{SHH}$ signaling networks and divergent FGF effects. Development 136, 1443-1452.

Hu, B.Y., Du, Z.W., and Zhang, S.C. (2009b). Differentiation of human oligodendrocytes from pluripotent stem cells. Nat Protoc 4, 1614-1622.

Hu, B.Y., Weick, J.P., Yu, J., Ma, L.X., Zhang, X.Q., Thomson, J.A., 
and Zhang, S.C. (2010). Neural differentiation of human induced pluripotent stem cells follows developmental principles but with variable potency. Proc Natl Acad Sci U S A 107, 4335-4340.

Hu, B.Y., and Zhang, S.C. (2009). Differentiation of spinal motor neurons from pluripotent human stem cells. Nat Protoc 4, 1295-1304.

Kim, J., Efe, J.A., Zhu, S., Talantova, M., Yuan, X., Wang, S., Lipton, S.A., Zhang, K., and Ding, S. (2011). Direct reprogramming of mouse fibroblasts to neural progenitors. Proc Natl Acad Sci U S A 108, 7838-7843.

Krencik, R., Weick, J.P., Liu, Y., Zhang, Z.J., and Zhang, S.C. (2011). Specification of transplantable astroglial subtypes from human pluripotent stem cells. Nat Biotechnol 29, 528-534.

Lanner, F., and Rossant, J. (2010). The role of FGF/Erk signaling in pluripotent cells. Development 137, 3351-3360.

LaVaute, T.M., Yoo, Y.D., Pankratz, M.T., Weick, J.P., Gerstner, J.R., and Zhang, S.C. (2009). Regulation of neural specification from human embryonic stem cells by BMP and FGF. Stem Cells 27, 1741-1749.

Lee, G., Papapetrou, E.P., Kim, H., Chambers, S.M., Tomishima, M.J., Fasano, C.A., Ganat, Y.M., Menon, J., Shimizu, F., Viale, A., et al. (2009). Modelling pathogenesis and treatment of familial dysautonomia using patient-specific iPSCs. Nature 461, 402-406.

Li, X.J., Du, Z.W., Zarnowska, E.D., Pankratz, M., Hansen, L.O., Pearce, R.A., and Zhang, S.C. (2005). Specification of motoneurons from human embryonic stem cells. Nat Biotechnol 23, 215-221.

Lujan, E., Chanda, S., Ahlenius, H., Sudhof, T.C., and Wernig, M. (2012). Direct conversion of mouse fibroblasts to self-renewing, tripotent neural precursor cells. Proc Natl Acad Sci U S A 109, 2527-2532.

Ma, L., Hu, B., Liu, Y., Vermilyea, S.C., Liu, H., Gao, L., Sun, Y., Zhang, X., and Zhang, S.C. (2012). Human embryonic stem cell-derived GABA neurons correct locomotion deficits in quinolinic acid-lesioned mice. Cell Stem Cell 10, 455-464.

Marchetto, M.C., Muotri, A.R., Mu, Y., Smith, A.M., Cezar, G.G., and Gage, F.H. (2008). Non-cell-autonomous effect of human SOD1 G37R astrocytes on motor neurons derived from human embryonic stem cells. Cell Stem Cell 3, 649-657.

Marro, S., Pang, Z.P., Yang, N., Tsai, M.C., Qu, K., Chang, H.Y., Sudhof, T.C., and Wernig, M. (2011). Direct lineage conversion of terminally differentiated hepatocytes to functional neurons. Cell Stem Cell 9, 374-382.

Okita, K., and Yamanaka, S. (2006). Intracellular signaling pathways regulating pluripotency of embryonic stem cells. Curr Stem Cell Res Ther 1, 103-111.

Osafune, K., Caron, L., Borowiak, M., Martinez, R.J., Fitz-Gerald, C.S., Sato, Y., Cowan, C.A., Chien, K.R., and Melton, D.A. (2008). Marked differences in differentiation propensity among human embryonic stem cell lines. Nat Biotechnol 26, 313-315.

Pal, U., Chaudhury, S., and Sarkar, P.K. (1999). Tubulin and glial fibrillary acidic protein gene expression in developing fetal human brain at midgestation. Neurochemical research 24, 637-641.

Pang, Z.P., Yang, N., Vierbuchen, T., Ostermeier, A., Fuentes, D.R., Yang, T.Q., Citri, A., Sebastiano, V., Marro, S., Sudhof, T.C., et al. (2011). Induction of human neuronal cells by defined transcription factors. Nature 476, 220-223.
Pankratz, M.T., Li, X.J., Lavaute, T.M., Lyons, E.A., Chen, X., and Zhang, S.C. (2007). Directed neural differentiation of human embryonic stem cells via an obligated primitive anterior stage. Stem Cells 25, 1511-1520.

Pfisterer, U., Kirkeby, A., Torper, O., Wood, J., Nelander, J., Dufour, A., Bjorklund, A., Lindvall, O., Jakobsson, J., and Parmar, M. (2011). Direct conversion of human fibroblasts to dopaminergic neurons. Proc Natl Acad Sci U S A 108, 10343-10348.

Qiang, L., Fujita, R., Yamashita, T., Angulo, S., Rhinn, H., Rhee, D., Doege, C., Chau, L., Aubry, L., Vanti, W.B., et al. (2011). Directed conversion of Alzheimer's disease patient skin fibroblasts into functional neurons. Cell 146, 359-371.

Rao, M. (2004). Conserved and divergent paths that regulate self-renewal in mouse and human embryonic stem cells. Dev Biol 275, 269-286.

Ring, K.L., Tong, L.M., Balestra, M.E., Javier, R., Andrews-Zwilling, Y., Li, G., Walker, D., Zhang, W.R., Kreitzer, A.C., and Huang, Y. (2012). Direct reprogramming of mouse and human fibroblasts into multipotent neural stem cells with a single factor. Cell Stem Cell 11, 100-109.

Rossant, J. (2008). Stem cells and early lineage development. Cell 132, 527-531.

Sato, N., Sanjuan, I.M., Heke, M., Uchida, M., Naef, F., and Brivanlou, A.H. (2003). Molecular signature of human embryonic stem cells and its comparison with the mouse. Dev Biol 260, 404-413.

Sheng, C., Zheng, Q., Wu, J., Xu, Z., Wang, L., Li, W., Zhang, H., Zhao, X.Y., Liu, L., Wang, Z., et al. (2012). Direct reprogramming of Sertoli cells into multipotent neural stem cells by defined factors. Cell Res 22, 208-218.

Son, E.Y., Ichida, J.K., Wainger, B.J., Toma, J.S., Rafuse, V.F., Woolf, C.J., and Eggan, K. (2011). Conversion of mouse and human fibroblasts into functional spinal motor neurons. Cell Stem Cell 9, 205-218.

Takahashi, K., Tanabe, K., Ohnuki, M., Narita, M., Ichisaka, T., Tomoda, K., and Yamanaka, S. (2007). Induction of pluripotent stem cells from adult human fibroblasts by defined factors. Cell 131, 861-872.

Tesar, P.J., Chenoweth, J.G., Brook, F.A., Davies, T.J., Evans, E.P., Mack, D.L., Gardner, R.L., and McKay, R.D. (2007). New cell lines from mouse epiblast share defining features with human embryonic stem cells. Nature 448, 196-199.

Thier, M., Worsdorfer, P., Lakes, Y.B., Gorris, R., Herms, S., Opitz, T., Seiferling, D., Quandel, T., Hoffmann, P., Nothen, M.M., et al. (2012). Direct conversion of fibroblasts into stably expandable neural stem cells. Cell Stem Cell 10, 473-479.

Thomson, J.A., Itskovitz-Eldor, J., Shapiro, S.S., Waknitz, M.A., Swiergiel, J.J., Marshall, V.S., and Jones, J.M. (1998). Embryonic stem cell lines derived from human blastocysts. Science 282 , 1145-1147.

Vierbuchen, T., Ostermeier, A., Pang, Z.P., Kokubu, Y., Sudhof, T.C., and Wernig, M. (2010). Direct conversion of fibroblasts to functional neurons by defined factors. Nature 463, 1035-1041.

Wichterle, H., Turnbull, D.H., Nery, S., Fishell, G., and Alvarez-Buylla, A. (2001). In utero fate mapping reveals distinct migratory pathways and fates of neurons born in the mammalian basal forebrain. Development 128, 3759-3771.

Wilkinson, M., Hume, R., Strange, R., and Bell, J.E. (1990). Glial and 
neuronal differentiation in the human fetal brain 9-23 weeks of gestation. Neuropathol Appl Neurobiol 16, 193-204.

Wright, L.S., Prowse, K.R., Wallace, K., Linskens, M.H., and Svendsen, C.N. (2006). Human progenitor cells isolated from the developing cortex undergo decreased neurogenesis and eventual senescence following expansion in vitro. Exp Cell Res 312, 2107-2120.

Wu, H., Xu, J., Pang, Z.P., Ge, W., Kim, K.J., Blanchi, B., Chen, C., Sudhof, T.C., and Sun, Y.E. (2007). Integrative genomic and functional analyses reveal neuronal subtype differentiation bias in human embryonic stem cell lines. Proc Natl Acad Sci U S A 104, 13821-13826.

Xu, R.H., Chen, X., Li, D.S., Li, R., Addicks, G.C., Glennon, C., Zwaka, T.P., and Thomson, J.A. (2002). BMP4 initiates human embryonic stem cell differentiation to trophoblast. Nat Biotechnol 20, 1261-1264.
Yoo, A.S., Sun, A.X., Li, L., Shcheglovitov, A., Portmann, T., Li, Y., Lee-Messer, C., Dolmetsch, R.E., Tsien, R.W., and Crabtree, G.R. (2011). MicroRNA-mediated conversion of human fibroblasts to neurons. Nature 476, 228-231.

Yu, J., Vodyanik, M.A., Smuga-Otto, K., Antosiewicz-Bourget, J., Frane, J.L., Tian, S., Nie, J., Jonsdottir, G.A., Ruotti, V., Stewart, R., et al. (2007). Induced pluripotent stem cell lines derived from human somatic cells. Science 318, 1917-1920.

Zhang, S.C., Wernig, M., Duncan, I.D., Brustle, O., and Thomson, J.A. (2001). In vitro differentiation of transplantable neural precursors from human embryonic stem cells. Nat Biotechnol 19, 1129-1133.

Zhang, X., Huang, C.T., Chen, J., Pankratz, M.T., Xi, J., Li, J., Yang, Y., Lavaute, T.M., Li, X.J., Ayala, M., et al. (2010). Pax6 is a human neuroectoderm cell fate determinant. Cell Stem Cell 7 , 90-100. 